\title{
Children with complex chronic conditions: an evaluation from the standpoint of academic publications
}

\author{
Karinne M. Carvalho ${ }^{1 *}$, Mariana S. N. de Carvalho ${ }^{1}$, Rafaela L. Grando ${ }^{2}$, Lívia A. de Menezes ${ }^{1}$
}

\author{
${ }^{1}$ Instituto Nacional de Saúde da Mulher, da Criança e do Adolescente Fernandes Figueira/Fiocruz, Brazil - Rio de \\ Janeiro-RJ, Brazil \\ ${ }^{2}$ Observatório em Ciência, Tecnologia e Inovação em Saúde da Fundação Oswaldo Cruz/Fiocruz, Brazil - Rio de \\ Janeiro-RJ, Brazil
}

Received: 05 January 2021

Revised: 02 February 2021

Accepted: 04 February 2021

\section{*Correspondence:}

Dr. Karinne M. Carvalho,

E-mail: karinnemarieta@gmail.com

Copyright: (c) the author(s), publisher and licensee Medip Academy. This is an open-access article distributed under the terms of the Creative Commons Attribution Non-Commercial License, which permits unrestricted non-commercial use, distribution, and reproduction in any medium, provided the original work is properly cited.

\begin{abstract}
Children with complex chronic conditions (CCC) belong to a distinct pediatric group, characterized by the (potential) manifestation of a wide range of pathologies requires long-term multidisciplinary health care, alongside recurrent hospitalizations and, in many cases, dependent on the use of technology for life maintenance. The need to seek, organize and disseminate bibliographic information on CCC led us to chart the scientific production on this theme, and a complete search of the academic publications was conducted in two scientific databases, the Web of Science and Scopus. The results indicate a significant growth in CCC research over the years, matching both, the increased number of cases and the consequent rise in life expectancy of these children. The scientific production on CCC is concentrated in the United States of America, reflecting and discussing the access to the health system of that country. We observed that the main thematic areas of the publications were related to hospitalization, health needs, coordination of care and oral health. Children have inequitable levels of access to treatment for CCC, according to family income, place of residence, educational level, race/ethnicity, evidencing the urgent need for formulation and implementation of public policies that address this portion of the population. Thus, it is expected that the present study will serve as a bridge guide for the development of potential new research projects, actions to promote and stimulate studies on this relevant theme and so far, neglected.
\end{abstract}

Keywords: Children with complex chronic conditions, Life-limiting illness, Childhood disability, Bibliometric mapping

\section{INTRODUCTION}

The terms complex chronic condition (CCC) or complex medical conditions are derived from the broad category of children with special health care needs (CSHCN). Described in 1998 by McPherson et al after extensive consultation with the US Department of Maternal and Child Health, CSHCN stands for children affected by or at high risk of developing chronic physical, developmental, behavior, or emotional dysfunctions, and require specialized health care and services. This is a vast and heterogeneous group, presenting variable clinical complexity, has functional limitations, and uses health resources to varying degrees. ${ }^{1}$

In 2001, the U.S. National Academy of Medicine - known as the Institute of Medicine (IoM) until 2015 recommended the agency for health care research and quality (AHRQ) to list the 15 priorities in public health regarding the occurrence of diseases, their burden and 
demand for resources. The CSHCN was described as the priority population. $^{2}$

As its prevalence has increased worldwide, many subsequent studies aimed to identify which subgroup of CSHCN exhibited greater clinical vulnerability, thus requiring greater use of health services and resources. Thereof the complexity feature had to be inserted in the panorama of chronic conditions, encouraging several authors worldwide to dedicate themselves to this research field and the improvement of care for this particular group.

Also, in 2001, Feudtner published one of the most important definitions on the complexity of chronic conditions. ${ }^{3}$ It deemed children with complex chronic conditions a subgroup of those who have chronic health conditions and have the following common characteristics: presence of any disease, with a minimum expected duration of 12 months (unless death is the previous outcome); and involvement of more than one organ or system, or solely one organ severely affected, requiring specialized follow-up and probably a period of hospitalization in a tertiary care hospital.

In 2003, the World Health Organization (WHO) defined chronic health conditions as "problems that require continuous management for a period of several years or decades and that cover a broad category of diseases" and therefore require a reorganization of health services and new care-related strategies that support patients, particularly those in the growth and human development stages with all their specificities. ${ }^{4,5}$

Currently, the literature considers the existence of 12 categories of CCCs, based on the International Classification of Diseases, tenth revision (ICD-10). Ten categories are related to the organs and/or systems primarily affected: neurological and/or neuromuscular conditions; respiratory tracts; cardiovascular diseases; and/or urological; gastrointestinal disorders; haematological and/or immunological; metabolic diseases; related to congenital anomalies or genetic defects; malignancy and related to prematurity and the neonatal period. The other two categories (technology dependent and transplanted organs or tissues) can also be classified as subcategories of large organs and/or affected systems concomitantly. ${ }^{6}$

It is likely that, when adopting these paradigms, we get to restricted interpretations regarding the health needs of this population, so that some authors prefer to highlight the dimensions that make up their conceptual framework. Cohen et al. (2011) propose four common domains, based on their similarities: a lifelong chronic disease, often incurable, so severe that it can affect multiple organs and/or body systems; significant limitation in the ability to perform basic bodily functions, including (however not limited to) ability to eat, drink, breathe, etc.; the need for numerous health service providers (e.g., specialists, therapists, home nurses, etc.) and treatments for health maintenance; and high use of health resources through numerous outpatient consultations, medical prescriptions, recurrent hospital admissions and visits to emergency services. $^{7}$

Several terminologies are used in contemporary literature to refer to this subpopulation. Generally, the term child is used accompanied by two or more of the following words: complex, chronic, medical, clinical, condition and/or needs. For example: children with complex chronic conditions, with complex medical needs, with complex medical conditions, with complex health conditions or even children with medical complexity. ${ }^{7}$

The expression technology-dependent child often refers to an even smaller subgroup of children with CCC, when the technology occurs in the context of a physical limitation and the attempt to compensate for the loss of a vital function. Several devices and/or apparatuses are commonly utilized such us tracheostomy, gastrostomy, peritoneal ventricle shunt, ventilatory support in various modalities and long-stay catheters for intravenous drugs of continuous use. The repercussions of caring for a technology-dependent child are diverse, surpass physical adversities and always permeate the emotional, social and financial dimensions. ${ }^{8}$

Brazil has been marked over the last three decades by the strong presence of chronic illnesses in childhood and adolescence, attributed to the impact of the demographicepidemiological transition, a phenomenon that was already observed, years before, in European countries and North America. ${ }^{9,10}$

Even in the face of such a complex scenario in child health - in which some infectious diseases, malnutrition and perinatal health problems still occupy a prominent place and compete with the strong presence of congenital anomalies - in 2015, complex chronic conditions were included in the child health agenda, in Brazil. ${ }^{11}$ Thus, CCCs became the strategic axis IV of action of the National Policy for Integral Attention to Children's Health (PNAISC), established within the scope of the Brazilian Unified Health System (SUS). This strategic measure constitutes an important step to enhance the visibility of this group of children and adolescents. They often spend months to years under treatment in hospitals, invisible to the society. ${ }^{12}$

The PNAISC also recognizes that it is a challenge to reconcile an agenda of public commitments that equitably addresses multiple assistance care requirements, organizational and research demands of this "new pediatric practice". ${ }^{13}$

\section{METHODOLOGY}

A complete search of the academic publications was conducted in two scientific databases, the Web of Science and Scopus. Due to the complexity of the theme, the 
combination of these two databases was used to cover as many documents as possible. Since the intention is an overview of CCC there was no temporal restriction. Pediatricians, researchers and other health professionals have used different definitions to report pediatric patients with complex conditions. ${ }^{7,14-17}$ Therefore, we first identified the main terminologies used to refer to these children. This strategy is important to track the theme, being a fundamental step to guarantee the return of the largest possible number of publications. The following keywords were used for the search: "pediatric complex care", "child* with medical complexity", "child* with special health needs", "child* with complex chronic conditions" e "technology-dependent child*". There was also the combination of the terms "complex chronic conditions", "technology dependent medical complexity", "special health care" with words related to children since this is the focus of the study: infant, child*, kids, pediatric. The search was centered on the title, abstract and keywords of the publications.

The results of these searches were unified by means of the VantagePoint ${ }^{\circledR}$ software for cleaning and harmonization of the data, resulting in 3,271 relevant publications. VOS viewer software, version 1.6.14, was used for the information and map the distribution of the main thematic areas. VOS viewer is mainly intended to analyze bibliometric networks through visualization of similarities. ${ }^{18}$ The construction of the correlation map in the VOS viewer software was made by inserting the abstracts and titles of the publications. With the grouping of terms that often co-occur in the same publications, clusters were created where similar co-occurrences gain strength and are close. ${ }^{19}$ We considered a minimum recurrence of 30 times and only terms with $60 \%$ or more relevance were selected.

\section{RESULTS AND DISCUSSION}

\section{Temporal evolution}

The analysis of scientific articles is an important tool to understand the process of knowledge construction, since it allows the identification of trends over time around a subject, as well as the geographical distribution by countries, institutions and experts involved in a given research line. These assessments showed a marked growth of academic interest in research involving CCC.

Figure 1 shows that scientific publications in this area have been growing steadily over the years, in the wake of the advances in medicine and medical technologies, as well as improvements in health care. Improvements in health care resulted in a significant increase in the survival rate of children with severe conditions at birth or those who survived for a short time. ${ }^{20}$ More research emerged seeking to understand these life-threatening conditions and provide evidence to future public health interventions.
The first publication on CCC found in this study dates from 1966, and in the 1990s, the interest of the scientific community raised systematically. Since the 2000s, the debate on this group of children grew in importance, especially after 2001, when the IoM recognized the relevance of the CCCs thus improving their visibility. Figure 1 shows the peak in 2004 concurring with the WHO's recognition of chronic conditions as a broad category of diseases which requires continuous management over years or decades. Thereof, the focus has been on condition control with patient-centered care rather than cure. ${ }^{2}$ This document called upon the reorganization of health systems, the insertion of chronically ill patients in the international agenda, the expansion and encouragement to further dialogue and studies involving CCCs., ${ }^{9,13,21,22}$ In 2005, with these higher figures of publications and the forecast of a significant increase for the following years, WHO published a new document aimed at guiding and preparing health workers to deal with the challenges of escalating number of chronic conditions in the 21 st century. The document also identified the level of competencies to match the needs of patients and their families. ${ }^{23}$ The documents mentioned above corroborated the forthcoming need for research on children living with CCC. As a result, there was a sharp growth in the number of publications.

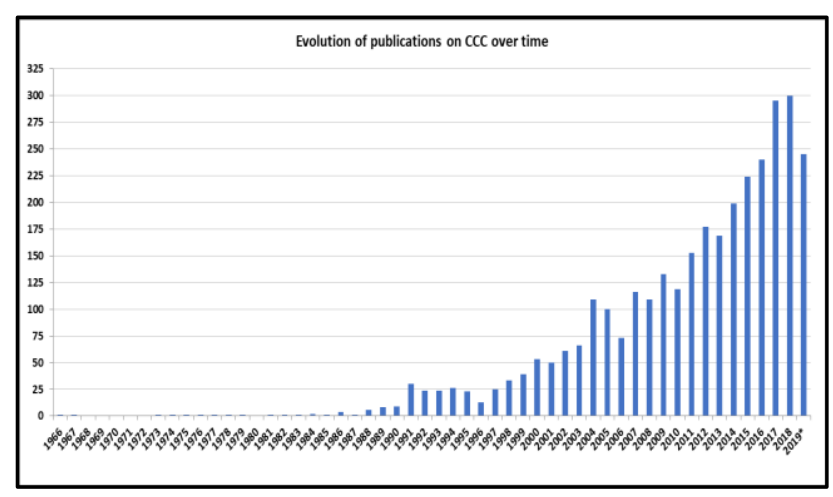

Figure 1: Number of publications filed per year for children with complex chronic conditions.

The year 2019 shows a sharp drop in numbers of publications, likely due to the period of the data collection carried out in September 2019

\section{Leading countries}

Over the period covered in this analysis, the United States of America (USA), Canada, and the United Kingdom led the production of knowledge on CCC. However, the scenario is shown in Figure 2 points to an absolute dominance of North American countries in research involving CCC. Of the total of 3,271 documents retrieved for this study, 2,372 were conducted in North American institutions, $73 \%$ of the world production on the subject, which represents a 10 fold figure when compared to Canada, the second country, with 232 occurrences ( $7 \%$ of world production), followed by the United Kingdom (142) and Australia (91 occurrences). 
Over the years, Brazil has contributed with 62 publications on CCCs, which corresponds to $2 \%$ of world production. This production is still timid and very scattered over the wide field of chronic health conditions. Many of these articles are focused on the care of specific pathologies, notably chronic kidney diseases, congenital heart diseases and cancer. This result indicates that research and political strategies focused on the patient, and his health needs, are still insufficient. ${ }^{24}$

The strong publishing leadership of the USA on CCCs seems to be causally related to the peculiarities of their health system and the economic impact that this group of the society have on the health services throughout life. They are prone to frequent and recurrent hospital admissions, "overuse of services", thus generating a significant burden on the American health system and their families. Medicaid is the program offered by the USA to low-income families who are unable to pay for private health insurance. The Children Health Insurance Program (CHIP) was structured to explicitly serve children from families with modest incomes that do not qualify for Medicaid. $^{25}$

In the USA, about 14.2 million children (19\%) have special health needs. These children endure a variety of conditions that require long-term health services to maintain life and/or improve quality of life. Analysis by the Kaiser Family Foundation shows that less than half of this group (48\%) have Medicaid/CHIP coverage, while the other $52 \%$ need private insurance to access treatments. Furthermore, private insurances in the USA do not cover the full range of services that children with CCC and their families require, leaving this population with some unmet needs. ${ }^{26}$

Although CSHCNs are considered to be of little quantitative significance, they represent a large part of health expenditures in the USA: it is estimated that this group of children consume approximately $80 \%$ of the resources allocated to health in childhood, which makes them a priority in public health. ${ }^{27,28}$

Data for the year 2013 show that the annual expenditure of Medicaid per child with chronic health conditions was $\$ 17,831$, seven times higher than the expenses with healthy children, which was $\$ 2,484 .{ }^{26}$ According to Simon, in 2006, children with CCCs accounted for $10 \%$ of all admissions to pediatric hospitals, $40 \%$ of hospital expenses and $70 \%$ to $90 \%$ of the use of technologies in $2006 .^{29}$

There is also a group of children, of extreme gravity, classified as children in catastrophic conditions for whom the presence of specialized teams and multiple services are indispensable for their survival. They represent a rather small and progressively enlarging group. Over the last decade, it accounted for $0.4 \%$ of the total childhood population, spent $11 \%$ of the health budget and $24 \%$ of the resources allocated to hospitals. ${ }^{30,31}$

\section{Main thematic areas of publications}

We retrieved 3,271 academic publications which were organized in a map of co-occurrences of words in the titles and abstracts. Each color in Figure 3 corresponds to a cluster. We highlight four clusters addressing different dimensions of the publications on CCC: the dimension of hospitalization and the impacts on the lives of children and their families, as well as on the health system; the extent of common health needs - as well as inequities; the dimension of coordinated care between healthcare levels and the dimension related to dental care and oral health.

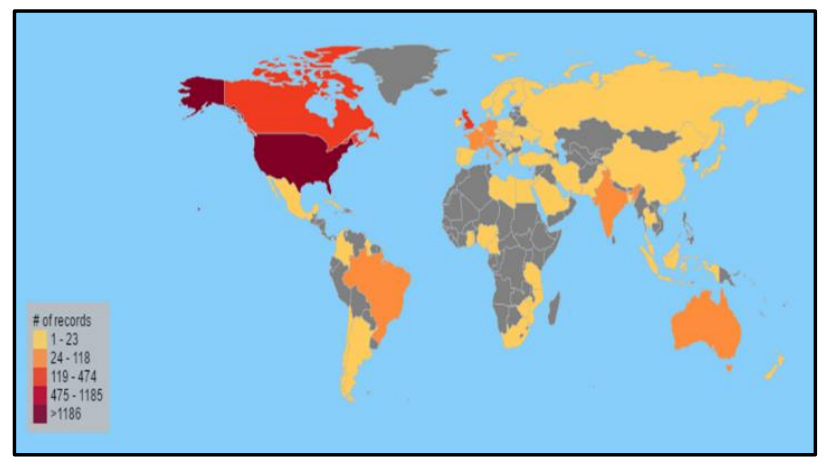

Figure 2: Countries with the largest number of articles published in the field of children with complex chronic conditions.

\section{Hospitalization (cluster 1) and health needs (cluster 2)}

Many of the studies focused on two clusters, clearly linked to each other. The red cluster refers to hospitalization and the stemming impact on the lives of children and their families and, on the health system, especially with regard to costs and the co-occurrence of compound words such as: hospital, hospitalization, hospital admission, hospital readmission, hospitalized child, cost and patient.

The blue cluster refers to the health needs of this group of children, explicitly addressing access to treatments, as they need a comprehensive coverage of long-term medical care and services that ought to cover their families. It is also related to health inequities concerning race/ethnicity, the place of residence, social vulnerability, health insurance coverage, the status of public policies, which hinder the access of a portion of these children to adequate treatment. The prevalence of children with $\mathrm{CCC}$ has increased significantly over time due to advances in science and subsequent survival rates. If, on the one hand, this survival is a gain for this group, on the other hand, it highlights the health disparities present in this population.

The fact that they are recurrently admitted to hospitals throughout life, often for long periods, the costs of dependence, the use of multiple health services, with emphasis on constant access to complementary, comprehensive and coordinated care, impacts the health system and reveals the urgency of a reformulation of services for these children. The impact on the health 
system associated with hospitalization - often a health care need for these children - have been the subject of several studies, especially in the USA, which holds more than $70 \%$ of the knowledge produced on this subject worldwide. $^{20,29,32-38}$

\section{Coordination of care (cluster 3)}

The green cluster is related to the coordination of care, with an emphasis on home care and its interfaces. The shift of children from the hospital to the family environment creates many challenges for caregivers as pediatric patients with special health needs require complex and continued care. There are numerous advantages for the patient's home-based care if the continuity is ensured. Complex chronic conditions in childhood have a devastating effect on patients' quality of life, but this reality also directly impacts their caregivers who, due to accessibility issues, but also stigma and prejudice, often deprive themselves of social interaction. They are not rarely forced to leave their jobs to take care full-time, which generates stress, anxiety and depression of caregivers, making clear the need for home-based, familyoriented care.

The relevance of a coordinated support network is evident. It needs the involvement of specialized physicians and the society in general for the emotional adaptation to the caring process and well-being of parents. The commitment and collaborative network between health professionals and caregivers are crucial to the success of prolonged treatments. Seeking to improve these processes, several studies focused on this approach have shown that this is the only thorough, feasible and effective system of knowledge, guidance and partnership to improve accessibility, quality, efficiency and continuity of health care for this population. The development of research in this thematic area is of fundamental importance, since they provide evidence for the planning, guidance and care strategies for families facing the daily challenges of treating children with special health needs..$^{20,39-43}$

\section{Oral health (cluster 4)}

A less evident group, visualized on the term map by the yellow cluster, points to another theme that stood out in the prospective analysis within the $\mathrm{CCC}$ care line, the oral health of these children. Words such as teeth, oral health, pediatric dentist, general anesthesia, dental treatment, young child, SHCN (special health care needs) cooccurred, indicating that the physical and/or cognitive deficiencies of this group may result in a higher risk of buccal diseases. These are likely to be aggravated, given the difficulties in seeking oral prophylactics and dental treatments. Factors related to a geographic location such as rural or hard-to-reach housing, family resistance, family income, fear, anxiety, and patients' severe condition become barriers to obtain oral health care in children with CCC. As a result, children enrolled in Medicaid who have special health needs are the least likely to seek preventive dental care.

Another issue is the difficulty in finding dentists willing and or trained to provide adequate care. Often this group of children needs general anesthesia to be given the necessary oral treatment. ${ }^{44-51}$

It is important to emphasize that dental care is the most prevalent neglected health need among all children in the USA. The IoM has notified the importance of oral health and made recommendations to address the challenges surrounding disparities in access to oral health by needy people and vulnerable populations. Access barriers also exist amongst people living in rural areas and people with disabilities, regardless of their financial resources. These unmet dental needs result in a high prevalence of caries. ${ }^{52-}$ 54

The map of co-occurrences suggests that the challenge of dentistry in the care line of these children has also been the subject of studies. However, due to the importance of this type of treatment in the quality of life and the difficulty in finding trained and willing professionals to assist this group, the knowledge gap remains noticeable and more research on access to oral health and the impact of this unmet need to be carried out.

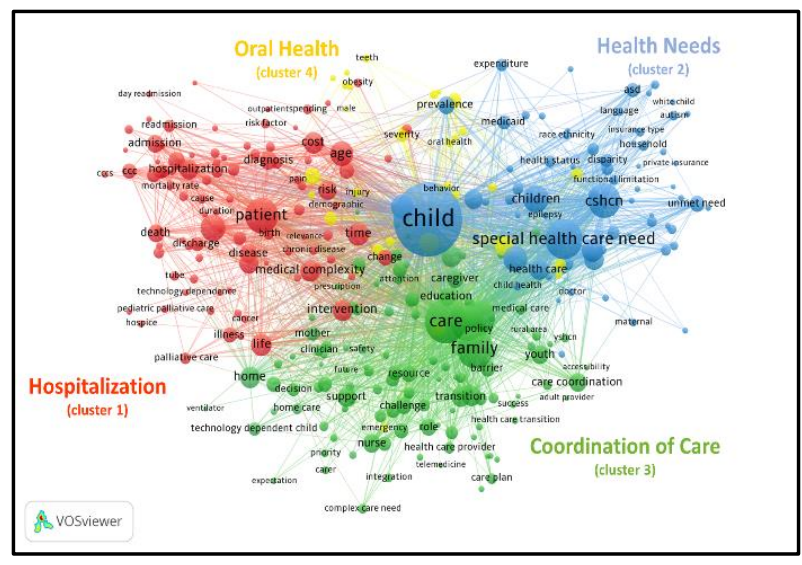

Figure 3: Term map of CCC publications. The map shows the main terms extracted from titles and abstracts. The size of each node indicates the number of publications and their matching terms.

\section{CONCLUSION}

We chose the term complex chronic condition (CCC) instead of others commonly used in the literature to refer to this group. We shared the opinion that we will not always be facing a disease that requires treatment, but rather circumstances in people's health conditions requiring specific challenges faced by health professionals, health systems and users. Also, the complexity approach is not restricted to the field of medicine but rather situated in the broad field of health. 
Children and adolescents with CCCs use multiple specialized services, which need coordination for quality care and require high levels of resources in their treatment. Often require more than one specialized doctor involved in their clinical management, in addition to the multidisciplinary team, such as rehabilitation, psychological support and social work.

Children and adolescents with CCCs need services that have an interface with family care and protection, as it continuously plays a caregiver role. The care plan for these patients should be oriented to the family as a unit.

The focus and organization of a therapeutic plan is essential and reorients all the guidelines of care for this population because the main point is no longer the cure, but rather the maintenance and improvement of their health status and quality of their life.

The hospital care path bears most of the health expenses, as well as the medicines and supplies necessary for their maintenance, almost always acquired through more than one source of funding.

When planning and managing hospital discharges of patients with CCCs, the consequences go throughout and beyond the health system. If the length of hospital stays is too long, there is a reduced number of beds within the health network and consequently a shortage of their availability for the treatment of acute diseases.

Prospecting in a bibliographic database consists of mapping based on historical information. The bibliometric tools used here to analyze and trace the world research involving children with CCCs pointed to a progression in research involving CCC over time. This is one of the most efficient ways to bring to light the future needs of investigating this theme, yet to be further explored and possibly underfunded over the research investment horizon. It is unquestionable that scientific publications need continuous development so that new knowledge in a scientific domain can be set to improve the quality of life of children and their families. In the face of adversity, risks and vulnerability throughout the process can be cruel. Knowingly, in the universe of these patients there is no expectation for cure.

A strong concentration of knowledge has been verified in the USA. This expertise is due to the need to obtain significant clinical results capable of providing gain in the quality of life of this population, in addition to the need to plan adequate health care. The disparity in access to treatment for CSHC (children with special health conditions) is a reality in the USA due to the peculiarities of their health system. Still, disparities in access to treatment regardless of financial condition, race/ethnicity or housing location and standards is also a reality in poor countries.
The clusters underscore the main thematic areas of studies but within each cluster there are subthemes to be researched. It is important to note that the smaller the node within the cluster, the greater the existing gap over that knowledge. The size of each node indicates the number of publications that have the corresponding term in their title or abstract.

The results presented here can contribute as a guideline for the formulation of public policies and/or research direction. It provides a significant amount of systematic information to the scientific community working in the areas directly or indirectly involved with CCCs.

Funding: No funding sources

Conflict of interest: None declared

Ethical approval: Not required

\section{REFERENCES}

1. McPherson $\mathrm{M}$, Arango $\mathrm{P}$, Fox $\mathrm{H}$, Lauver $\mathrm{C}$, McManus M, Newacheck PW, Perrin JM, Shonkoff JP, Strickland B. A new definition of children with special health care needs. Pediatrics. 1998;102(1):137-40.

2. Adams K, Corrigan JM. Priority Areas for National Action: Transforming Health Care Quality. Institute of Medicine (US) Committee on Identifying Priority Areas for Quality Improvement. Washington (DC): National Academies Press (US); 2003.

3. Feudtner C, Hays RM, Haynes G, Geyer JR, Neff JM, Koepsell TD. Deaths attributed to pediatric complex chronic conditions: national trends and implications for supportive care services. Pediatrics. 2001;107(6):99.

4. Organização Mundial da Saúde (OMS). Cuidados inovadores para condições crônicas: componentes estruturais de ação: Relatório Mundial. Brasília, 2003.

5. Gomes MASM. Saúde da Criança e do Adolescente no Brasil: realidade e desafios. Residência Pediátrica. 2011;1:35-7.

6. Feudtner C, Feinstein JA, Zhong W, Hall M, Dai D. Pediatric complex chronic conditions classification system version 2: updated for ICD-10 and complex medical technology dependence and transplantation. BMC Pediatrics. 2014;14:199.

7. Cohen E, Kuo DZ, Agrawal R, Berry JG, Bhagat SK, Simon TD, Srivastava R. Children with medical complexity: an emerging population for clinical and research initiatives. Pediatrics. 2011;127:529-38.

8. Spratling R. Defining technology dependence in children and adolescents. Western J Nurs Res. 2015;37:634-51.

9. Moreira MEL, Goldani MZ. A criança é o pai do homem: novos desafios para a área de saúde da criança. Ciência \& Saúde Coletiva. 2010;15:321-7.

10. Goldani MZ. The impact of demographic and epidemiological transition in the health of children 
and adolescents in Brazil. Rev HCPA \& Fac Med Univ Fed Rio Gd do Sul. 2012;32:49-57.

11. Gomes MASM. As políticas públicas na área da saúde da criança. Ciência \& Saúde Coletiva. 2010;15:329-30.

12. Carvalho MSN de. Desospitalização de crianças com condições crônicas complexas: perspectivas e desafios. In: Desospitalização de crianças com condições crônicas complexas: perspectivas e desafios. 2019.

13. Brasil. Ministério da Saúde. Portaria No 1.130, de 05 de agosto de 2015. Institui a Política Nacional de Atenção Integral à Saúde da Criança (PNAISC) no âmbito do Sistema Único de Saúde (SUS). 2015.

14. Cohen, E. Status complexicus? The emergence of pediatric complex care. Pediatrics. 2018;141:202-11.

15. Berry JG. The landscape of medical care for children with medical complexity. Overland Park, KS: Children's Hospital Association. 2013;7.

16. Lin JL, Cohen E, Sanders LM. Shared decision making among children with medical complexity: results from a population-based survey. J Pediatr. 2018;192:216-22.

17. Kuo DZ. Recognition and management of medical complexity. Pediatrics. 2016;138:20163021.

18. Van Eck N, Waltman L. Software survey: VOSviewer, a computer program for bibliometric mapping. Scientometrics. 2010;84:523-38.

19. Van Eck N, Waltman L. How to normalize cooccurrence data? An analysis of some well-known similarity measures. J Am Soc Information Sci Technol. 2009;60:1635-51.

20. Bjur KA, Wi CI, Ryu E, Crow SS, King KS, Juhn YJ. Epidemiology of Children With Multiple Complex Chronic Conditions in a Mixed Urban-Rural US Community. Hosp Pediatr. 2019;9(4):281-90.

21. Moreira MCN. Guidelines for a line of care for children and adolescents with complex chronic health conditions. Cadernos de Saúde Pública. 2017;33.

22. Hall DE. The care of children with medically complex chronic disease. J Pediatr. 2011;159:17880 .

23. World Health Organization. Preparing a health care workforce for the 21st century: the challenge of chronic conditions. World Health Organization 2005.

24. Rodrigues JLSQ, Portela MC, Malik AM. Agenda para a pesquisa sobre o cuidado centrado no paciente no Brasil 2019.

25. United States. Centers for Medicare \& Medicaid Services. Children's Health Insurance Program. Available at: https://www.healthcare.gov/medicaidchip/. Accessed on: 25 July 2020.

26. Musumeci M, Foutz J. Medicaid's role for children with special health care needs: a look at eligibility, services, and spending. Henry J Kaiser Family Foundation. 2018;22.

27. Elixhauser A, Machlin SR, Zodet MW, Chevarley FM, Patel N, McCormick MC, Simpson L. Health care for children and youth in the United States: 2001 annual report on access, utilization, quality, and expenditures. Ambul Pediatr. 2002;2(6):419-37.

28. Newacheck PW, Kim SE. A national profile of health care utilization and expenditures for children with special health care needs. Arch Pediatr Adolescent Med. 2005;159:10-7.

29. Simon TD, Berry J, Feudtner C, Stone BL, Sheng X, Bratton SL, et al. Children with complex chronic conditions in inpatient hospital settings in the United States. Pediatrics. 2010;126(4):647-55.

30. Neff JM, Sharp VL, Muldoon J, Graham J, Myers K. Profile of medical charges for children by health status group and severity level in a Washington State Health Plan. Health Serv Res. 2004;39(1):73-89.

31. Berry JG, Agrawal R, Kuo DZ, Cohen E, Risko W, Hall M, et al. Characteristics of hospitalizations for patients who use a structured clinical care program for children with medical complexity. J Pediatr. 2011;159(2):284-90.

32. Cohen E. Patterns and costs of health care use of children with medical complexity. Pediatrics. 2012;130:1463-70.

33. Casey PH, Lyle RE, Bird TM, Robbins JM, Kuo DZ, Brown C, et al. Effect of hospital-based comprehensive care clinic on health costs for Medicaid-insured medically complex children. Arch Pediatr Adolesc Med. 2011;165(5):392-8.

34. Carlton EF, Barbaro RP, Iwashyna TJ, Prescott HC. Cost of Pediatric Severe Sepsis Hospitalizations. JAMA Pediatr. 2019;173(10):986-7.

35. Peltz, A. Hospital utilization among children with the highest annual inpatient cost. Pediatrics. 2016;137.

36. Berry JG, Hall M, Neff J, Goodman D, Cohen E, Agrawal R, Kuo D, Feudtner C. Children with medical complexity and Medicaid: spending and cost savings. Health Aff (Millwood). 2014;33(12):2199206.

37. Markham JL, Hall M, Gay JC, Bettenhausen JL, Berry JG. Length of Stay and Cost of Pediatric Readmissions. Pediatrics. 2018;141(4):20172934.

38. Pérez-Ardanaz B, Morales-Asencio JM, GarcíaPiñero JM, Lupiáñez-Pérez I, Morales-Gil IM, Kaknani-Uttumchandani S. Socioeconomic Status and Health Services Utilization for Children With Complex Chronic Conditions Liable to Receive Nurse-Led Services: A Cross-Sectional Study. J Nurs Scholarsh. 2019;51(5):518-25.

39. Dias BC. Challenges of family caregivers of children with special needs of multiple, complex and continuing care at home. Escola Anna Nery. 2019;23.

40. Dionísio R. Papel de cuidador no contexto da hospitalização domiciliária: diagnóstico, implementação e monitorização de intervenção. Revista INFAD de Psicologia. Int J Develop Educ Psychol. 2019;1:365-72.

41. Cheng N, Ma J, Ding W, Zhang Y. Effects of caregiver-involved interventions on the quality of life of children and adolescents with chronic conditions and their caregivers: a systematic review and metaanalysis. Qual Life Res. 2019;28(1):13-33. 
42. Foster CC, Agrawal RK, Davis MM. Home health care for children with medical complexity: workforce gaps, policy, and future directions. Health Affairs. 2019;38:987-93.

43. Toledano-Toledano F, Domínguez-Guedea MT. Psychosocial factors related with caregiver burden among families of children with chronic conditions. Bio Psycho Social Med. 2019;13:6.

44. Nelson, LP. Unmet dental needs and barriers to care for children with significant special health care needs. Pediatr Dentistr. 2011;33:29-36.

45. Oredugba FA, Akindayomi Y. Oral health status and treatment needs of children and young adults attending a day centre for individuals with special health care needs. BMC Oral Health. 2008;8:30.

46. Du RY, Yiu CKY, King NM. Oral health behaviours of preschool children with autism spectrum disorders and their barriers to dental care. J Autism Develop Disord. 2019;49:453-9.

47. Wilson NJ. Oral health status and reported oral health problems in people with intellectual disability: A literature review. J Intellect Develop Disability. 2019;44:292-304.

48. Casamassimo PS, Seale NS, Ruehs K. General dentists' perceptions of educational and treatment issues affecting access to care for children with special health care needs. J Dent Educ. 2004;68:238.

49. Norwood KW Jr, Slayton RL, Council on Children With Disabilities, Section on Oral Health. Oral health care for children with developmental disabilities. Pediatrics. 2013;131(3):614-9.

50. Craig MH, Scott JM, Slayton RL, Walker AL, Chi DL. Preventive dental care use for children with special health care needs in Washington's Access to Baby and Child Dentistry program. J Am Dent Assoc. 2019;150(1):42-8.

51. Oredugba FA, Akindayomi Y. Oral health status and treatment needs of children and young adults attending a day centre for individuals with special health care needs. BMC Oral Health. 2008;8:30.

52. Mouradian WE, Wehr E, Crall JJ. Disparities in children's oral health and access to dental care. JAMA. 2000;284:2625-31

53. Zhou N, Wong HM, Mcgrath C. Oral health and associated factors among preschool children with special healthcare needs. Oral Dis. 2019;25:1221-8.

54. Martin AB, Brand M. Oral Health Chronic Disease Integration: The Call for a New Public Health Systems Approach for Dental Research. Madridge J Dent Oral Surg. 2016;1:21-2.

Cite this article as: Carvalho KM, de Carvalho MSN, Grando RL, de Menezes LA. Children with complex chronic conditions: an evaluation from the standpoint of academic publications. Int J Contemp Pediatr 2021;8:594-601. 